\title{
Early identification and intervention services for children with autism in Vietnam
}

\begin{abstract}
BACKGROUND
In high income countries in Europe and North America, early identification and intervention for autism spectrum disorders (ASD) have been linked to improved long-term outcomes. However, in most low and middle income countries (LMIC) little is known about the use or availability of such services, which limits the ability of policy and development planning. The purpose of the present study was to assess the use of ASD services in a number of cities in Vietnam, an Asian LMIC, in order to identify areas within the field that should be specifically targeted to improve ASD services in Vietnam.
\end{abstract}

\section{PARTICIPANTS AND PROCEDURE}

Surveys were conducted in six different cities across Vietnam with 90 parents/caregivers of children with ASD, 115 professionals working with children with ASD, and $10 \mathrm{di}-$ rectors of agencies providing ASD services. The parents/ caregivers' survey assessed demographics and information regarding their child's symptoms and services the child received. The professionals' survey assessed their demographic and professional background, the ASD services they provide, and their perspective on the quality of ASD services at their agency. The directors' survey included these same questions as well as additional questions regarding the operation of the agency.

RESULTS

Early identification and intervention ASD services are available in Vietnam, at least in major cities. However, there is a lack of well-trained professionals, the tools used for evaluation and diagnosis are limited, outdated and unstandardized, and the quality of services is questionable. Most importantly, a scientific evidence base for services is absent, and the country lacks an official governmental policy for supporting children with ASD.

\section{CONCLUSIONS}

Research directly assessing the quality of ASD services in Vietnam is needed. Most importantly, efforts at facilitating governmental policy and support advocacy are needed to increase the likelihood that families and children with ASD will receive appropriate and effective services.

KEY WORDS

ASD; early intervention; early identification; autism; Vietnam

ORGANIZATIONS - 1: Vietnam National University, Hanoi, Vietnam · 2: Vanderbilt University, Nashville, Tennessee, USA .

3: Hanoi National University of Education, Hanoi, Vietnam · 4: VinSchool, Hanoi, Vietnam · 5: Vietnam Institute

of Educational Sciences, Vietnam

AUthors' CONTRIBUtion - A: Study design - B: Data collection - C: Statistical analysis - D: Data interpretation .

E: Manuscript preparation · F: Literature search · G: Funds collection

CORRESPonding AUthor - Cong Van Tran, Ph.D., Vietnam National University, School of Education, 144 Xuan Thuy Road,

Cau Giay District, Hanoi, Vietnam, e-mail: congtv@vnu.edu.vn

to Cite this ARTICle - Tran, C. V., Weiss, B., Khuc, T. N., Tran, T. T. L., Nguyen, T. T. N., Nguyen, H. T. K., \& Dao, T. T. T.

(2015). Early identification and intervention services for children with autism in Vietnam. Health Psychology Report,

3(3), 191-200. DOI: 10.5114/hpr.2015.53125

RECEIVED 05.05.2015 - REVIEWED 05.06.2015 - ACCEPTED 16.07.2015 • PUBLISHED 31.07.2015 


\section{BACKGROUND}

Autism, more formally known as "autism spectrum disorders” (ASD) (American Psychiatric Association, 2013), is a severe neurodevelopmental disorder that begins very early in life. It involves a triad of impairments including delay and deviance in (a) social interaction and relationships, (b) communication and language, and (c) restricted interests and repetitive behaviors (Faja \& Dawson, 2006). The specific caus-
Cong Van Tran, Bahr Weiss, Toan Nang Khuc, Thu Thi Le Tran, Trang Thi Nha Nguyen,

Hoa Thi Kim Nguyen,

Thuy Thi Thu Dao es of ASD have not yet been identified, but there is strong evidence that to a large degree genetic factors underlie its development in many but likely not all cases (Roberts \& Prior, 2006). It is clear that autism generally is present at birth or shortly thereafter, with professionals able to diagnose children with ASD as young as two years of age (i.e., Stone et al., 1999; Lord, 1995) or even 18 months (Samango-Sprouse et al., 2014).

Autism spectrum disorders can range from very mild (with little need for external support) to very severe (American Psychiatric Association, 2013). Children with mild ASD may be able to develop coping strategies that essentially control the secondary effects of their ASD symptoms. However, in part because of its core deficits in social communication and social interaction, ASD often is highly debilitating, severely impacting an individual's overall life functioning (Russell, 1997; Shattuck et al., 2012; Eaves \& Ho, 2008). Some studies (e.g., Bailey, Hatton, Mesibov, Ament, \& Skinner, 2000) have reported that individuals with ASD have more difficulties in all aspects of living than any other mental health disability (e.g., intellectual disabilities).

The apparent prevalence rate of autism has increased significantly since the earliest epidemiologic studies were conducted in the late 1960s and early 1970s, when studies in Europe and the U.S. suggested a prevalence of around 1 in 2,500 children (Gillberg \& Wing, 1999); by the 2000s, prevalence estimates from large surveys were 1-2\% (Lai, Lombardo, \& Baron-Cohen, 2013; Schieve et al., 2012). Most recently a study by the U.S. Centers for Disease Control (CDC) in 2010 reported that the overall prevalence of ASD at the U.S. ADDM sites was 14.70 per 1,000 (one in 68) children aged 8 years. Autism spectrum disorders prevalence estimates varied across sites from 0.0057 to 0.0219 , and also by sex and racial/ethnic group. Globally, an ASD prevalence estimate of about $1 \%$ is generally accepted (Blumberg et al., 2013).

To help children with ASD it is essential to focus on the earliest years of development, as early learning powerfully affects the child's future life course due to the significance of the impairments associated with ASD (Roberts \& Prior, 2006). Small amounts of relative improvement in early childhood can have a substantial impact on a child's later adulthood func- tioning (Woods \& Wetherby, 2003), with a large body of research indicating that early identification and intervention can change the development trajectory of children with ASD (Matson \& Minshawi, 2006). Thus, early identification has become "best practice", since it helps families gather information about their child's disorder and needs, and to begin treatment (Volkmar \& Pauls, 2003). Early intervention is critical for preventing the cascade of effects in which early deficits impair later functioning.

A number of assessment tools are available for early identification (e.g., the CHAT [Checklist for Autism in Toddlers]; the updated M-CHAT; Robins, Barton, \& Green, 2001; Robins \& Dumont-Mathieu, 2006; Robins, 2008). However, although there is strong research supporting the reliability and validity of these measures, most of this research has been conducted in high income countries (HIC) such as those in Western Europe, the U.K., the U.S., etc. Similarly, most of the research regarding the effectiveness of early intervention for ASD has been conducted in HIC, where the programs are well structured, supported by the government, and focus on the use of evidenced-based methods (Samms-Vaughan, 2014). In contrast, in low and middle income countries (LMIC) where the majority of the world's population lives, there has been relatively little research and development of valid tools and interventions for ASD (Daley, 2002).

The present study focuses on Vietnam, an Asian LMIC of about 93 million people. As with most LMIC, relatively little is known in Vietnam about the support services available for individuals with ASD. Some small surveys, primarily students' dissertations or master's theses, more generally focused on intellectual disability than on ASD per se, have assessed early identification and intervention services in different centers and schools in Vietnam (Tran, 2015). The little research directly focusing on autism conducted in Vietnam has been mostly published in Vietnamese in conferences proceedings, and is not available more broadly to the global mental health field, which limits its ability to support ASD in Vietnam through the global health movement. In one of the few studies published in an English language journal, $\mathrm{Vu}$, Whittaker, Whittaker, and Rodger (2014) reported that within Vietnam, ASD is culturally and socially constructed as a 'karmic demerit' or 'family problem' rather than a lifelong developmental disorder needing support from the government. They also found that parents of children with ASD had little access to services for their children. A related factor that negatively affects families' access to early identification and intervention services is social awareness. Even primary school teachers and medical students have limited understanding of ASD (Trinh \& Tran, 2014; Vu $\&$ Tran, 2014). In a non-data-based review published in the Vietnamese Journal of Social Sciences, Nguy- 
en (2012) discussed some important aspects of ASD evaluation and diagnosis in Vietnam, commenting that major limitations in regard to ASD services included the unavailability of standardized diagnostic tools, and a lack of specific national standards for professionals. In the Ho Chi Minh City Sciences Journal, Le (2014) discussed the ASQ (Ages and Stages Questionnaire) screening tool and how it can be used for early identification and intervention for children with special needs. However, both articles were theoretical, without empirical data. Overall, there has not been empirical study of support services available for individuals with ASD in Vietnam. The purpose of the present study thus was to assess the practices of early identification and intervention for children with ASD in Vietnam, an important step for improving service quality for this population. Because ASD is not considered a disability by the Vietnamese, such research identifying the needs of families with a child with ASD will be important for raising the awareness of policy makers of the strong need for services. In addition, at present in training programs for special education, school psychology, early childhood education, etc. in a number of different universities in Vietnam, ASD has been identified as an important area that students should study. Thus, information regarding various stakeholders' perceptions about ASD services will be very useful to help guide and improve these ASD training programs.

\section{PARTICIPANTS AND PROCEDURE}

\section{SITES, PARTICIPANTS, AND RECRUITMENT}

Ten participating agencies were selected from six cities in Vietnam (Hanoi, Bac Ninh, Phu Yen, Hai Phong, Ninh Binh, and Danang) that represented major urban areas in the northern and central regions of the country. A convenience sample was used, with agencies providing ASD services identified based on the authors' professional networks, which included primary, secondary, and tertiary education, mental health and psychology, and medicine. Agency directors were contacted and the study discussed with them. All directors were interested in participating, and were sent packets including the study description, consent forms, a package of questionnaires, etc. Agency directors distributed invitation letters, consents forms, and survey packages to interested professionals in the agency and interested families receiving services at the agency. Study participants included 90 parents/caregivers (hereafter referred to as 'caregivers'), 115 professionals, and 10 site directors from these ten participating agencies. The average age of caregivers was 34 years, and 59\% were female. As is typical in Vietnam (Weiss et al., 2014), the large majority (92\%) of caregivers were married. Participant characteristics are reported in Table 1.
The study was approved by the U.S. FWA IRB \#18223 at Vietnam National University.

\section{INSTRUMENTS}

Items for the survey were adapted from the New York State Department of Early Intervention (1999)

Table 1

Participant characteristics

\begin{tabular}{|c|c|}
\hline \multicolumn{2}{|l|}{ Caregivers } \\
\hline Age (years) & $\begin{array}{c}M=34(S D=5.43) \\
\text { range: } 23-49\end{array}$ \\
\hline Female & $60 \%$ \\
\hline \multicolumn{2}{|l|}{ Marital status } \\
\hline married & $92 \%$ \\
\hline single & $2 \%$ \\
\hline divorced & $5 \%$ \\
\hline separated & $1 \%$ \\
\hline \multicolumn{2}{|l|}{ Education } \\
\hline $\begin{array}{l}\text { graduated high school } \\
\text { or lower }\end{array}$ & $31 \%$ \\
\hline bachelor degree & $51 \%$ \\
\hline master or higher & $18 \%$ \\
\hline \multicolumn{2}{|l|}{ Occupational status } \\
\hline full time & $70 \%$ \\
\hline part-time & $16 \%$ \\
\hline unemployed & $14 \%$ \\
\hline Relationship to child & $97 \%$ parents \\
\hline \multicolumn{2}{|l|}{ Children (with ASD) } \\
\hline Age (years) & $\begin{aligned} M= & 5.29(S D=2.79), \\
& \text { range: } 2-17\end{aligned}$ \\
\hline Female & $12 \%$ \\
\hline \multicolumn{2}{|l|}{ Professionals } \\
\hline Age (years) & $\begin{aligned} M= & 30.82(S D=9.21), \\
& \text { range: } 22-65\end{aligned}$ \\
\hline Female & $86 \%$ \\
\hline $\begin{array}{l}\text { Years working in ASD } \\
\text { field }\end{array}$ & $M=6.06(S D=7.50)$ \\
\hline \multicolumn{2}{|l|}{ Education } \\
\hline $\begin{array}{l}\text { community college } \\
\text { degree }\end{array}$ & $15 \%$ \\
\hline bachelor's degree & $57 \%$ \\
\hline master's degree & $18 \%$ \\
\hline \multicolumn{2}{|l|}{ Agency directors } \\
\hline Age & $\begin{array}{c}M=31(S D=7.42) \\
\text { range: } 23-49\end{array}$ \\
\hline Female & $90 \%$ \\
\hline $\begin{array}{l}\text { Years' experience as } \\
\text { director }\end{array}$ & $\begin{array}{c}M=2.40(S D=0.97) \\
\text { range: } 1-6\end{array}$ \\
\hline \multicolumn{2}{|l|}{ Education } \\
\hline $\begin{array}{l}\text { community college } \\
\text { degree }\end{array}$ & $10 \%$ \\
\hline bachelor's degree & $80 \%$ \\
\hline master's degree & $10 \%$ \\
\hline
\end{tabular}

Early identification and intervention services

Note. ASD - autism spectrum disorders 
Cong Van Tran, Bahr Weiss, Toan Nang Khuc, Thu Thi Le Tran, Trang Thi Nha Nguyen,

Hoa Thi Kim Nguyen,

Thuy Thi Thu Dao study. Items for ASD symptoms were adapted from $\mathrm{M}$-CHAT. Content validity was assessed based on ICD/DSM criteria through a review conducted by a research team that included both Vietnamese and U.S. professionals. Three meetings that discussed the content of each item and the three scales relative to ICD/ DSM criteria were conducted. Items and scales went through several revisions before data collection began. Internal consistency for all scales used in the survey was acceptable or better, ranging from .73 to .93.

Caregivers' Survey. The caregivers' survey assessed demographic information about themselves and their child with ASD, and the ASD services that the child had received as well as caregivers' evaluation of those services. Caregivers also reported on this child's ASD (and related behavioral problems such as aggression) symptoms, focusing on the three

Table 2

Caregivers' report of their child's autism spectrum disorders symptoms

\begin{tabular}{ll}
\hline Symptoms & $\%$ \\
\hline Delayed or no language & 77 \\
$\begin{array}{l}\text { Lack of ability to start and maintain } \\
\text { conversations }\end{array}$ & 76 \\
$\begin{array}{l}\text { Hyperactive, inattentive } \\
\text { Unable to establish social relationships }\end{array}$ & 73 \\
$\begin{array}{l}\text { Deficient in non-verbal communication } \\
\text { (eye contact, facial expression, etc.) }\end{array}$ & 63 \\
$\begin{array}{l}\text { Lack of emotional and social interac- } \\
\text { tions }\end{array}$ & 63 \\
$\begin{array}{l}\text { Stereotyped or repetitive behaviors } \\
\text { Not sharing own interests, activities, } \\
\text { etc. with others }\end{array}$ & 63 \\
$\begin{array}{l}\text { Doesn't engage in pretend or role play- } \\
\text { ing games }\end{array}$ & 61 \\
$\begin{array}{l}\text { Uses abnormal and repetitive language } \\
\text { Playing with toys monotonously/incor- } \\
\text { rectly }\end{array}$ & 57 \\
$\begin{array}{l}\text { Preoccupied with parts of objects in- } \\
\text { stead of whole }\end{array}$ & 56 \\
$\begin{array}{l}\text { Little or no joint attention } \\
\text { Overly attached to objects or routines } \\
\text { Over-sensitive to certain sensory stimuli } \\
\text { (e.g. sound, smell) }\end{array}$ & 36 \\
$\begin{array}{l}\text { Abnormal dietary habits } \\
\text { Self-stimulation (e.g. auditory, visual) }\end{array}$ & 18 \\
\hline & 50 \\
\hline
\end{tabular}

classical ASD symptom domains (American Psychiatric Association, 2000; World Health Organization, 2002): impaired language, impaired social interactions, and stereotyped behaviors and interests. Caregivers rated their child's improvement in language, motor skills, social interactions skills, etc., since beginning ASD services, on a Likert scale ranging from 1 (not at all improved) to 5 (greatly improved).

Professionals' Survey. The professionals' survey assessed their demographic and professional background (e.g., education, work experience), the services provided at their agency, and their perspective regarding the quality of services at their agency.

Directors' Survey. The directors' survey similarly assessed their perspective on the services provided by their agency, and the professionals providing the services as well as their perceptions about the operation of the agency.

\section{RESULTS}

\section{CHILD CHARACTERISTICS AND SYMPTOMS}

Children's age at receiving their ASD diagnosis ranged from 17 months to 8 years, with the mean age at diagnosis of 2.56 years (30.63 months, $S D=15.40)$. The majority of children (66\%) started their intervention before the age of 3 , with $32 \%$ starting intervention between 3 and 6 years old, and $2 \%$ starting when older than 6. Most children (81\%) received their diagnosis at a pediatric hospital, with $14 \%$ of children receiving their ASD diagnosis at a private center, and $4 \%$ never having received an official diagnosis (although they started receiving intervention services from their agency). Among those who were diagnosed, $46 \%$ of children were given their ASD diagnosis by a specialized medical doctor (usually a psychiatrist), $26 \%$ by psychology staff, $24 \%$ by a pediatrician, and $4 \%$ by teachers.

Table 2 lists the ASD and related symptoms reported by caregivers. The most frequently reported symptom was delayed or no language $(77 \%)$, and the least frequently reported symptom was self-stimulation behaviors (18\%). Table 3 reports the percentages of children lacking symptoms in 1 or more key ASD symptom domains (language impairment; social re-

Table 3

Percentage of children lacking symptom in autism spectrum disorders domain

\begin{tabular}{lc}
\hline A. Language impairment & $8 \%$ \\
$\begin{array}{l}\text { B. Social relationship / interaction im- } \\
\text { pairment }\end{array}$ & $16 \%$ \\
C. Stereotyped behaviors and interests & $11 \%$ \\
One or more domain (A, B and/or C) & $26 \%$ \\
\hline
\end{tabular}


lationship/interaction impairment; stereotyped behavior and interests). Over $25 \%$ of the caregivers' reports for their child labeled as having ASD did not include one or more key ASD symptom domains. Eight percent of children were not reported to have any language impairment, $16 \%$ were not reported to have any social relationship/interaction impairment, and $11 \%$ were not reported to have any stereotyped behaviors or interests, although these are all key criterion domains for ASD. In regard to related behavioral problems, $73 \%$ of caregivers reported that their children were "hyperactive or inattentive", and $29 \%$ reported that their child had "aggressive/violent behaviors".

Table 4 reports caregivers' evaluation of the improvement they had seen in their child's ASD symptoms since beginning services, on a 1 (not at all improved) to 5 (very improved) scale. The mean for most domains was near the mid-point on the scale, with the domain with the highest level reported improvement being motor skills $(M=3.16)$, and the two areas with the lowest level of reported improvement being adaptive skills $(M=2.44)$ and social interaction skills $(M=2.29)$.

\section{CHARACTERISTICS OF PROFESSIONALS AND AGENCIES}

Among the sample of professionals, $72 \%$ were intervention teachers (similar to special education teachers in high income countries), $13 \%$ psychology staff, $5 \%$ social workers, and $1 \%$ medical doctors, with the rest holding non-health related degrees. The majority of professionals had a bachelor's degree (57\%), with $18 \%$ with a master's degree or higher, and $15 \%$ with a community college (3-year) degree. Forty-three percent of professionals worked at a Special Education Center (schools specifically for children with developmental disabilities), and another $43 \%$ worked
Table 4

Caregiver ratings improvement in autism spectrum disorders (ASD) symptoms since beginning ASD services

\begin{tabular}{lcl}
\cline { 1 - 2 } Domains of improvement & $M(S D)$ & \\
\cline { 1 - 2 } Motor skills & $3.13(1.47)$ & \\
Intellectual and cognitive skills & $3.08(1.42)$ & \\
Academic and learning skills & $3.03(1.10)$ & \\
Behavioral problem solving skills & $2.97(1.15)$ & \\
Language & $2.71(1.43)$ & Early \\
Adentification & \\
Adaptation skills & $2.44(1.37)$ & and intervention \\
Social interaction skills & $2.29(1.34)$ &
\end{tabular}

Note. Likert scale ranged from 1 (not at all improved) to 5 (greatly improved).

at a Psychology Support Center (which the focus on mental health problems more broadly rather than only on developmental disabilities). The mean number of children receiving services at their agencies was 29 , ranging from 8 to 60 children. All sites provided full-day treatment, $88.90 \%$ also provided individual session intervention (i.e., the child came to the center for 1-2 hours/day for treatment) and $33.30 \%$ provided home-based intervention; only $10.00 \%$ provided inclusive education services (i.e., non-diagnosed children also attended classes).

As part of their surveys, professionals and agency directors were asked about difficulties faced in providing effective services for families and children with ASD in Vietnam. "Facility difficulties" (i.e., problems with the physical space or resources at the center) were most frequently selected as a major difficulty (see Table 5). Perhaps not surprisingly, professionals and agency directors differed in regard to professionals' low salary as a major difficulty (with $50 \%$ vs. $30 \%$ of the two groups respectively selecting this as a major difficulty). Perhaps reflecting their dif-

Table 5

Professionals' and agency directors' evaluation of challenges in providing effective autism spectrum disorders service

\begin{tabular}{lcc}
\hline & \% professionals selecting & \% directors selecting \\
\hline Inadequate governmental policy & 25 & 60 \\
Lack of parental collaboration & 39 & 10 \\
Lack of well-trained teachers/therapists & 44 & 60 \\
Lack of standardized programs & 44 & 40 \\
Lack of valid, culturally appropriate tools & 46 & 40 \\
Financial difficulties (professionals' low salary) & 50 & 30 \\
Facility difficulties & 56 & 70 \\
Lack of experts & 57 & 30 \\
\hline
\end{tabular}


ferent roles in ASD services, $60 \%$ of agency directors saw a lack of government policy as a major difficulty, whereas only $25 \%$ of professionals did.

\section{AUTISM SPECTRUM DISORDERS SERVICES}

As part of their survey, caregivers reported the amount of time per week that their child received ASD services, which was on average about 25 hours of ASD services per week. Table 6 lists the ASD evaluation and planning tools that professionals reported using. Most notably, none of the ASD tools generally regardBahr Weiss, Toan Nang Khuc, Thu Thi Le Tran, Trang Thi Nha Nguyen, Hoa Thi Kim Nguyen,

Thuy Thi Thu Dao

\section{Table 6}

Tools used by professionals to assess autism spectrum disorders

\begin{tabular}{ll}
\hline Tool & $\%$ \\
\hline Small Steps & 53 \\
Denver-II & 50 \\
CHAT / M-CHAT & 49 \\
CARS & 39 \\
ASQ & 37 \\
PEP-R & 36 \\
Raven & 32 \\
ABS-S:2 & 27 \\
WISC-III/IV & 24 \\
PEP-3 & 24 \\
\hline
\end{tabular}

Note. Denver-II - Denver II Developmental Screening Test; (M-)CHAT - (Modified) Checklist for Autism in Toddlers; CARS - Childhood Autism Rating Scale; ASQ - Ages \& Stages Questionnaire; PEP-R (or 3) - Psychoeducational Profile-Revised (or Third Edition); Raven - Raven's Progressive Matrices ABS-S:2 - Adaptive Behavior Scale-School: 2; WISC-III/IV - Wechsler Intelligence Scale for Children - Third Edition/Fourth Edition.

Table 7

Caregiver report of approaches used to assess autism spectrum disorders

\begin{tabular}{lc}
\hline Assessment approach & $\%$ \\
\hline $\begin{array}{l}\text { Evaluation of pregnancy, birth and } \\
\text { post-birth history }\end{array}$ & 31 \\
$\begin{array}{l}\text { Evaluation of family history } \\
\text { Evaluation of birth defects or physical } \\
\text { injuries }\end{array}$ & 18 \\
$\begin{array}{l}\text { Behavioral evaluation } \\
\text { Psycho-neurology (e.g. EEG) evalua- } \\
\text { tion }\end{array}$ & 86 \\
$\begin{array}{l}\text { Biological / medical tests (blood, urine, } \\
\text { etc.) }\end{array}$ & 82 \\
\hline
\end{tabular}

ed in HIC as being of the highest validity (i.e., ADOS; Lord et al., 2000; ADI-R; Lord, Rutter, \& Le Couteur, 1994; Rutter, Le Couteur, \& Lord, 2003) were reported being used by any of the Vietnamese professionals. Table 7 lists parents' report of the assessment approaches used to evaluate their child's ASD. Most notable in these data is the fact that $18 \%$ of the children did not receive a behavioral evaluation, which is essential for correct ASD diagnosis and evaluation. Table 8 lists the early intervention services reported by professionals to have been provided to children with ASD. Most notable in this table is that $10 \%$ of professionals reported providing psychoanalysis to children with ASD.

In their survey the caregivers were asked to evaluate the quality of the services their child received and related factors (e.g., governmental policy). Similar to the agency directors, the area that caregivers saw as the weakest was governmental policy. The areas that they saw as the strongest were the expertise and professionalism of the agency and service providers (see Table 9).

\section{DISCUSSION}

This is one of the first studies in Vietnam examining early identification and intervention services for families and children with ASD, and there appear to be several positive aspects. Most children receiving services at the participating centers were identified relatively early, with the median age below 3 years, which is positive given that early identification and intervention services are a key factor in successful intervention with ASD (Woods \& Wetherby, 2003; GorDon, 2009; Camarata, 2014). It is important to note, of course, that although perhaps representative of Vietnamese children actually receiving ASD services (given that there are few ASD centers outside the major urban areas we sampled; Nguyen, 2013), our sample certainly is not representative of children with ASD in Vietnam in general: Given (a) interna-

Table 8

Autism spectrum disorders intervention approaches reported used by professionals

\begin{tabular}{ll}
\hline & $\%$ \\
\hline Psychoanalysis & 10 \\
Medication and medical intervention & 13 \\
Physical therapy & 24 \\
Sensory and motor therapy & 67 \\
Cognitive behavior therapy & 68 \\
Inclusive education & 77 \\
Speech therapy & 83 \\
Behavior therapy & 87 \\
\hline
\end{tabular}


tional ASD prevalence rates of approximately $1 \%$, (b) the overall Vietnamese population of approximately 93 million, and (c) the relatively small number of sites providing ASD services in Vietnam (Nguyen, 2013), the vast majority of children in Vietnam with ASD undoubtedly are not receiving any services, early or otherwise. In regard to the representativeness of our sample more generally, the median level of education in Vietnam is about the $8^{\text {th }}$ grade (Weiss et al., 2014), whereas in our sample the median education was about two years of college. The likely effect of this is that our parents were more knowledgeable about autism than the typical parent in Vietnam with a child with autism (Tran, 2015).

It is encouraging that caregivers reported that their child with ASD was receiving a moderate number of hours of services per week, on average about 25 , which suggests that in Vietnam children with ASD who are receiving services receive a reasonable amount. It also is encouraging that caregivers reported small to moderate levels of improvement in their child's ASD symptoms across various domains. Although these are of course not objective observations and it is not possible to attribute actual change in the child's functioning to the intervention since there were no comparison groups, the statistics are nonetheless encouraging. Generally speaking, as reported in Table 9, caregivers reported that the quality of the services that their child was receiving was fair to good.

Other aspects of our results were less encouraging, however. Over 25\% of the caregivers' reports on their child's ASD symptoms lacked one or more key ASD symptom domain (American Psychiatric Association, 2000; World Health Organization, 2002), raising the question of whether their child actually had ASD and questioning the validity of the diagnosis and the competency of the individuals who provided the diagnosis. A related concern is that $16 \%$ of the caregivers reported that as part of their ASD assessment their child did not receive a behavioral evaluation, which is a central and necessary component of an ASD assessment (Filipek et al., 2000; Johnson \& Myers, 2007). Furthermore, most of the assessment tools that the professionals reported using are outdated and have not been adapted, validated, and standardized for Vietnam, with the exception of the WISC-IV (Dang, Weiss, Pollack, \& Nguyen, 2011). It is also concerning that $10 \%$ of professionals reported using psychoanalysis with children with ASD: Psychoanalysis has not been found to be more effective than placebo treatment conditions for any mental health disorder (Herbert, Sharp, \& Gaudiano, 2003), and the likelihood of psychoanalysis providing benefit for a complex neuro-developmental disorder such as autism is low. Over $2 / 3$ of the professionals reported using cognitive-behavioral therapy (CBT) with children with ASD. Although CBT has been found to be effective for a range of mental health problems such as anxiety
Table 9

Caregivers' evaluation of their child's autism spectrum disorders services, and factors impacting on their child's services

$$
M(S D)
$$

Government policies supporting ASD services

Scientific and systematic base of ASD evaluation

Diversity and appropriateness of ASD interventions

Early

Comprehensiveness of information for parents

Reliability and validity of ASD diagnosis

Scientific and systematic base for ASD intervention

Effectiveness of ASD intervention

Methods for collaborating with parents

Educational environment of the agency

Effectiveness of ASD agencies' support for families

ASD agencies' professionalism

Degree/education and experience of ASD assessment providers

ASD intervention service providers' professionalism

Degree/education and experience of ASD therapists/teachers

$3.54(1.08)$

Note. Ratings were made on a 1 (very poor) to 5 (very good) scale; ASD - autism spectrum disorders.

and depression (e.g., Sze \& Wood, 2008; Wood et al., 2008), there is little evidence regarding its utility with children with ASD. Cognitive-behavioral therapy is highly verbal, involving complex interpersonal communication and analysis, and thus probably would not be appropriate for individuals with ASD (Ames $\&$ Weiss, 2013). On the other hand, over $80 \%$ of the professionals did report using behavioral therapy and speech therapy, which are two central forms of intervention for ASD, in their work with individuals with ASD (Green et al., 2006; Sallows \& Graupner, 2005).

Another limitation for ASD services in Vietnam is the level of training among the professionals and agency directors. Less than $20 \%$ of the professionals and $10 \%$ of the agency directors had a master's degree or higher. Although effectively implementing a behavioral identification and intervention services 
Cong Van Tran, Bahr Weiss, Toan Nang Khuc, Thu Thi Le Tran, Trang Thi Nha Nguyen,

Hoa Thi Kim Nguyen,

Thuy Thi Thu Dao intervention (BI) plan for children with ASD does not require a graduate degree, at least in high income countries developing an effective BI plan often does (Hamad, Serna, Morrison, \& Fleming, 2010). The fact that only $10 \%$ of professionals worked in agencies that provided inclusive education services also is a limitation, given the importance of children with ASD interacting with non-diagnosed peers (Harrower \& Dunlap, 2001).

In this study, caregivers and professionals and agency directors identified what they believed to be the most serious obstacles or challenges to providing effective services for children with ASD in Vietnam. Agency directors most frequently identified facility difficulties (i.e., limitations in the physical infrastructure of the agency), a lack of governmental policy, and a lack of well-trained therapists and teachers as major obstacles. In the major urban areas from which our participants were recruited, because of the rapid urbanization that Vietnam is undergoing costs of land and hence rent can be quite high (Cuong, 2011), yet median national income, which controls what typical families can pay for services, is low (Weiss et al., 2014). Thus, it is difficult for ASD centers to afford appropriate physical facilities with sufficient space, technical tools, access to outdoor spaces for play, etc. A closely linked policy challenge, identified by the agency directors and caregivers as problematic, is the lack of formal governmental designation of "autism" as a disability (Vu et al., 2014), the consequence of which is that the national health insurance, which covers about $90 \%$ of Vietnamese citizens, does not cover ASD services. Similar to the directors, the professionals also most frequently identified facility difficulties, as well as a lack of experts, as major obstacles. The lack of experts probably reflects the fact that in order for professionals to receive effective ASD training, it is almost always necessary to have foreign experts travel to Vietnam to provide the training, which is challenging logistically as well as financially.

There are several strengths and weaknesses of the study that should be considered in order to most appropriately interpret our results. The fact that the study included caregivers, professionals and site directors from six different cities and 10 different agencies was a major strength, in that our results do not simply reflect the situation at a single agency or in a single city or region as has the very small existing literature in this area. This study intentionally did not survey sites outside the major urban areas, as there are few ASD agencies in the non-urban areas of Vietnam. However, the most serious limitation of the study, which also represents an important direction for future research, is the lack of objective evaluation of the quality of the services provided. Although caregivers generally appeared to view the services positively, the actual quality of the services is unclear, and there are reasons to have concerns. Another limitation of this study has to do with sample size, which consisting of 90 parents is quite small. However, this is the first study in Vietnam assessing ASD services to be published in an international, English language journal, so it still has some value for the field.

Given the limited state of autism services in Vietnam, a convenience sample was used with agencies selected based on the research team's network. The research team includes researchers and lecturers from a national research institute (the Institute of Educational Sciences) and a leading, national university (Vietnam National University). Because there is no national registry or licensure for health-related services in Vietnam at present, this unfortunately likely is the most realistic way to access private agencies in this field in Vietnam. In all likelihood, the effect of this sampling would be to increase the quality of the services provided, given that the agencies identified are probably relatively well established. Finally, the fact that as many as $10 \%$ of the professionals would consider it appropriate to use psychoanalysis with children with ASD is concerning. And although CBT is appropriate for many emotional and behavioral mental health disorders, it would generally not be considered as a primary therapy for ASD; the fact that over $2 / 3$ of the professionals reported using it with children with ASD raises concerns about the professionals' understanding of ASD and CBT.

An important focus for future research thus will be the objective assessment of the ASD services that children receive in the major urban areas of Vietnam. This can either be done through knowledge tests for providers, but most effectively through direct observation and objective ratings by trained coders of the services that agencies provide (Chevron \& Rounsaville, 1983). In addition, basic research and development of culturally valid assessment instruments, and evaluation of intervention programs through randomized designs, will be essential.

Ultimately, though, what will be necessary to increase the quality and quantity of services will be a change in governmental policy, to recognize ASD as a serious disability, services for which should be supported by the government. This will require additional research documenting the impaired functioning associated with children with ASD in Vietnam. This will also require research on how best to set up systematic and collaborative services among medicine, education, psychology and social work, and assess the influence of culture, family, and society on children with ASD in Vietnam, so that early identification and intervention services for ASD can be as effective as possible.

\section{REFERENCES}

American Psychiatric Association. (2000). Diagnostic and statistical manual of mental disorders ( $4^{\text {th }} \mathrm{ed}$., text rev.). Washington, DC: Author. 
American Psychiatric Association. (2013). Diagnostic and statistical manual of mental disorders ( $5^{\text {th }}$ ed.). Washington, DC: Author.

Ames, M., \& Weiss, J. (2013). Cognitive behaviour therapy for a child with autism spectrum disorder and verbal impairment: a case study. Journal of Developmental Disabilities, 19, 61-69.

Bailey, Jr, D. B., Hatton, D. D., Mesibov, G., Ament, N., \& Skinner, M. (2000). Early development, temperament, and functional impairment in autism and fragile X syndrome. Journal of Autism and Developmental Disorders, 30, 49-59.

Blumberg, S. J., Bramlett, M. D., Kogan, M. D., Schieve, L. A., Jones, J. R., \& Lu, M. C. (2013). Changes in prevalence of parent-reported autism spectrum disorder in school-aged U.S. children: 2007 to 2011-2012. National Health Statistics Reports, 65, 1-11.

Camarata, S. (2014). Early identification and early intervention in autism spectrum disorders: Accurate and effective? International Journal of Speech-Language Pathology, 16, 1-10.

Center for Disease Control and Prevention. (2014). Prevalence of autism spectrum disorders - Autism and Developmental Disabilities Monitoring Network, 14 sites, United States, 2010. MMWR 2014, 63 (No. SS-2).

Chevron, E. S., \& Rounsaville, B. J. (1983). Evaluating the clinical skills of psychotherapists: A comparison of techniques. Archives of General Psychiatry, 40, 1129-1132.

Cuong, N. V. (2011). Can Vietnam achieve the millennium development goal on poverty reduction in high inflation and economic stagnation? The Developing Economies, 49, 297-320.

Daley, T. C. (2002). The need for cross-cultural research on pervasive developmental disorders. Transcultural Psychiatry, 39, 532-551.

Dang, H. M., Weiss, B., Pollack, A., \& Nguyen, M. C. (2011). Adaptation of the Wechsler Intelligence Scale for Children-IV (WISC-IV) for Vietnam. Psychological Studies, 56, 387-392.

Eaves, L. C., \& Ho, H. H. (2008). Young adult outcome of autism spectrum disorders. Journal of Autism and Developmental Disorders, 38, 739-747.

Faja, S., \& Dawson, G. (2006). Early Intervention for Autism. In: J. Luby (ed.), Handbook of preschool mental health: Development, disorders, and treatment (pp. 388-416). New York City: Guilford Press.

Filipek, P. A., Accardo, P. J., Ashwal, S., Baranek, G. T., Cook, Jr., E. H., Dawson, G., Gordon, B., Gravel, J. S., Johnson, C. P., Kallen, R. J., Levy, S. E., Minshew, N. J., Ozonoff, S., Prizant, B. M., Rapin, I., Rogers, S. J., Stone, W. L., Teplin, S. W., Tuchman, R. F., \& Volkmar, F. R. (2000). Practice parameter: screening and diagnosis of autism: $\mathrm{Re}-$ port of the Quality Standards Subcommittee of the American Academy of Neurology and the Child Neurology Society. Neurology, 55, 468-479.
Gillberg, C., \& Wing, L. (1999). Autism: Not an extremely rare disorder. Acta Psychiatrica Scandanavia, 99, 399-406.

GorDon, D. (2009). Early intervention in autism. Neurology Now, 5, 23-26.

Green, V. A., Pituch, K. A., Itchon, J., Choi, A., O'Reilly, M., \& Sigafoos, J. (2006). Internet survey of treatments used by parents of children with autism. Research in Developmental Disabilities, 27, 70-84.

Hamad, C. D., Serna, R. W., Morrison, L., \& Fleming, R. (2010). Extending the reach of early intervention training for practitioners: A preliminary investigation of an online curriculum for teaching behavioral intervention knowledge in autism to families and service providers. Infants \& Young Children, 23, 195-208.

Harrower, J. K., \& Dunlap, G. (2001). Including children with autism in general education classrooms a review of effective strategies. Behavior Modification, 25, 762-784.

Herbert, J. D., Sharp, I. R., \& Gaudiano, B. A. (2003). Separating fact from fiction in the etiology and treatment of autism: A scientific review of the evidence. The Scientific Review of Mental Health Practice, 1, 23-43.

Johnson, C. P., \& Myers, S. M. (2007). Identification and evaluation of children with autism spectrum disorders. Pediatrics, 120, 1183-1215.

Lai, M. C., Lombardo M. V., \& Baron-Cohen, S. (2013). Autism. Lancet, 383, 896-910.

Le, H. T. M. (2014). ASQ - A screening tool for detecting and early intervention for children with special needs. HCMC Sciences Journal, 31, 218-226.

Lord, C. (1995). Follow-up of two-year-olds referred for possible autism. Journal of Child Psychology and Psychiatry, 36, 1365-1382.

Lord, C., Risi, S., Lambrecht, L., Cook, E. H., Leventhal, B. L., DiLavore, P. C., Pickles, A., \& Rutter, M. (2000). The Autism Diagnostic Observation Schedule-Generic: A standard measure of social and communication deficits associated with the spectrum of autism. Journal of Autism and Developmental Disorders, 30, 205-223.

Lord, C., Rutter, M., \& Le Couteur, A. (1994)., Autism Diagnostic Interview Revised: A revised version of a diagnostic interview for caregivers of individuals with possible pervasive developmental disorders. Journal of Autism and Developmental Disorders, 24, 659-685.

Matson, J. L., \& Minshawi, N. F. (2006). Early intervention for autism spectrum disorders: A critical analysis. Amsterdam: Elsevier Ltd.

New York State Department of Health, Early Intervention Program. (1999). Clinical practice guideline: Report of the recommendations. Autism/pervasive developmental disorders, Assessment and intervention for young children (age 0-3 years). Albany, NY: NYS Department of Health.
Early

identification and intervention services 
Nguyen, A. N. T. (2012). Some basic issues in ASDs diagnosis in Vietnam. VNU Journal of Social Sciences, 28, 143-147.

Nguyen, Y. H. T. (2013). Overview of care, rehabilitating, and education for children with ASD. Paper presented at the national symposium "Autism in Vietnam: Health and Educational Practices and Prospect". March 12-13 ${ }^{\text {th }} 2013$, Hanoi, Vietnam, 3-10.

Roberts, J. M. A., \& Prior, M. (2006). A review of the research to identify the most effective models of prac-
Cong Van Tran, Bahr Weiss, Toan Nang Khuc, Thu Thi Le Tran, Trang Thi Nha Nguyen,

Hoa Thi Kim Nguyen,

Thuy Thi Thu Dao tice in early intervention of children with autism spectrum disorders. Brisbane, Australia: Australian Government Department of Health and Ageing.

Robins, D. L. (2008). Screening for autism spectrum disorders in primary care settings. Autism, 12, 537-556.

Robins, D. L., Barton, M., \& Green, J. A. (2001). The modified checklist for autism in toddlers: An initial study investigating the early detection of autism and pervasive developmental disorders. Journal of Autism and Developmental Disorders, 31, 131-144.

Robins, D. L., \& Dumont-Mathieu, T. M. (2006). Early screening for autism spectrum disorders: update on the modified checklist for autism in toddlers and other measures. Journal of Developmental and Behavioral Pediatrics, 27, 111-119.

Russell, J. (1997). Autism as an executive disorder. New York City: Oxford University Press.

Rutter, M., LeCouteur, A., \& Lord, C. (2003). Autism Diagnostic Interview - Revised manual. Los Angeles, CA: Western Psychological Services.

Sallows, G. O., \& Graupner, T. D. (2005). Intensive behavioral treatment for children with autism: Fouryear outcome and predictors. Journal Information, 110, 417-438.

Samango-Sprouse, C. A., Stapleton, E. J., Aliabadi, F., Graw, R., Vickers, R., Haskell, K., Sadeghin, T., Jameson, R., Parmele, C. L., \& Gropman, A. L. (2014). Identification of infants at risk for autism spectrum disorder and developmental language delay prior to 12 months. Autism, 19, 327-337.

Samms-Vaughan, M. (2014). The status of early identification and early intervention in autism spectrum disorders in lower- and middle-income countries. International Journal of Speech-Language Pathology, 16, 30-35.

Schieve, L. A., Rice, C., Yeargin-Allsopp, M., Boyle, C. A., Kogan, M. D., Drews, C., \& Devine, O. (2012). Parent-reported prevalence of autism spectrum disorders in US-born children: An assessment of changes within birth cohorts from the 2003 to the 2007 National Survey of Children's Health. Maternal and Child Health Journal, 16, 151-157.

Shattuck, P. T., Narendorf, S. C., Cooper, B., Sterzing, P. R., Wagner, M., \& Taylor, J. L. (2012). Postsecondary education and employment among youth with an autism spectrum disorder. Pediatrics, 129, 1042-1049.
Stone, W. L., Lee, E. B., Ashford, L., Brissie, J., Hepburn, S. L., Coonrod, E. E., \& Weiss, B. H. (1999). Can autism be diagnosed accurately in children under 3 years? Journal of Child Psychology and Psychiatry, 40, 219-226.

Sze, K. M., \& Wood J. J. (2008). Enhancing CBT for the treatment of autism spectrum disorders and concurrent anxiety. Behavioural and Cognitive Psychotherapy, 36, 403-409.

Tran, C. V. (2015). The causes and current situation for children with developmental disorders in Vietnam. In: Policy for children with developmental disorders (pp. 4-13). Hanoi, Vietnam: World Vision International.

Trinh, H. T., \& Tran, C. V. (2014). Misperception of autism spectrum disorder among senior students in mental health care majors in Vietnam. Conference book "Mental health in school settings", organized by Young Psycho-educational Talent Fund June 2014 (pp. 159-175). HCMC VNU Publishing House.

Volkmar, F. R., \& Pauls, D. (2003). Autism. Lancet, 362, 1133-1141.

Vu, H. S., Whittaker, A., Whittaker, M., \& Rodger, S. (2014). Living with autism spectrum disorder in Hanoi, Vietnam. Social Science \& Medicine, 120, 278-285.

Vu, T. V., \& Tran, C. V. (2014). Hanoi kindergarten teachers' attitude towards autism spectrum disorder. Conference book "Mental health in school settings", organized by Young Psycho-educational Talent Fund June 2014. HCMC VNU Publishing house (pp. 486-496).

Weiss, B., Dang, M., Trung, L., Nguyen, M. C., Thuy, N. T. H., \& Pollack, A. (2014). A nationally-representative epidemiological and risk factor assessment of child mental health in Vietnam. International Perspectives in Psychology: Research, Practice, Consultation, 3, 139-153.

Wood, J. J., Drahota, A., Sze, K. M., Har, K., Chiu, A., \& Lange, D. A. (2008). Cognitive behavioral therapy for anxiety in children with autism spectrum disorders: A randomized, controlled trial. Journal of Child Psychology and Psychiatry, 50, 224-234.

Woods, J. J., \& Wetherby, A. M. (2003). Early identification of and intervention for infants and toddlers who are at risk for autism spectrum disorder. Language, Speech, and Hearing Services in Schools, 34, 180-193.

World Health Organization. (2002). Manual of the International Statistical Classification of the Diseases and Related Health Problems (10 ${ }^{\text {th }}$ ed.). Geneva: World Health Organization. 